\title{
Pola asuh dan budaya: Studi komparatif antara masyarakat urban dan masyarakat rural Indonesia
}

\author{
Inge Uli Wiswanti*, Ike Anggraika Kuntoro, Nisa Praditya Ar Rizqi, \& Lathifah Halim \\ Fakultas Psikologi, Universitas Indonesia, Kota Depok, Jawa Barat
}

\begin{abstract}
Abstrak
Pola asuh memiliki peran yang krusial dalam hampir seluruh aspek perkembangan anak, terutama aspek kognitif, emosi serta sosial. Perbedaan budaya dalam pola asuh, khususnya kemungkinan adanya perbedaan subkultur seperti etnis dan konteks urban serta rural masih jarang dieksplorasi. Penelitian ini bertujuan untuk menguji apakah memang terdapat perbedaan pola asuh antar etnis dan antar masyarakat urban (vs. rural) di Indonesia. Partisipan penelitian ini adalah perempuan yang sudah menjadi ibu. Sebanyak 383 perempuan dengan status ibu dari Jabodetabek $(\mathrm{N}=204)$, Magelang/Jawa $(\mathrm{N}=101)$ dan Bukittinggi/Minang $(\mathrm{N}=78)$ berpartisipasi dalam penelitian ini. Hasil utama penelitian menunjukkan adanya perbedaan yang signifikan antara nilai budaya (kolektivisme dan individualisme) serta praktek pengasuhan (conformity dan autonomy) di daerah urban dan rural. Dimensi kolektivisme, conformity dan autonomy menunjukkan perbedaan signifikan ketika dibandingkan pada tiga wilayah (Jabodetabek, Magelang, dan Bukittinggi). Jabodetabek cenderung lebih tinggi pada dimensi kolektivisme dan autonomy; Magelang pada dimensi conformity. Ketika variabel covariates dikontrol, maka dimensi individualisme menjadi signifikan bersama dengan dimensi kolektivisme, autonomy dan conformity.
\end{abstract}

Kata kunci: pola asuh, suku Jawa, suku Minang, masyarakat urban, masyarakat rural.

\begin{abstract}
Parenting practices have a pivotal role in children's development outcomes, particularly children's cognitive, emotional, and social development. Cultural differences in parenting practices, particularly the possibility of different subcultures such as ethnicity and urban and rural contexts, are rarely explored. This study aims to examine whether there are differences in parenting styles between ethnic groups and between urban (vs. rural) communities in the Indonesian context. The participants of this study were women who had become mothers. A total of 383 mothers resided in the Jakarta metropolitan area ( $\mathrm{N}=204)$, Magelang/Javanese $(\mathrm{N}=101)$, and Bukittinggi/Minangnese $(\mathrm{N}=78)$ participated in this study. The main result showed that there were significant differences between cultural values (collectivism and individualism) and parenting practices (conformity and autonomy) in urban and rural areas. Three dimensions (collectivist, conformity, and autonomy) had significant mean differences when compared in the Jakarta metropolitan area, Magelang, and Bukittinggi areas. Jakarta metropolitan area tends to be higher in collectivist and autonomy values; Magelang tends to be higher in conformity value. When covariates variables were controlled, the individualism value together with collectivism, conformity, and autonomy became significant in three areas.
\end{abstract}

Keywords: parenting practices, Javanese, Minangnese, urban area, rural areas.

\section{Pendahuluan}

Pola asuh merupakan serangkaian aktivitas kompleks yang terdiri dari perilaku-perilaku spesifik, yang berdiri sendiri maupun saling berinteraksi, yang dipraktekkan oleh orang tua lewat kegiatan sehari-hari bersama anaknya. Pola asuh yang diterapkan orang tua memiliki pengaruh yang krusial pada hampir keseluruhan aspek perkembangan anak, khususnya dalam aspek kognitif, emosi, dan sosial (Brooks, 2005; Morrison, 2009; Riany, Meredith, \& Cuskelly, 2017). Pengaruh

Naskah masuk: 29 November 2019

Naskah diterima: 20 Juli 2020 ini bisa positif (Alegre, 2012; Burchinal, PeisnerFeinberg, Pianta, \& Howes, 2002) maupun negatif (Smokowski, Bacallao, Cotter \& Evans, 2014; Vafaeenejad, Elyasi, Moosazadeh \& Shahhosseini, 2019).

Ada tiga faktor yang diketahui berperan terhadap pola asuh orang tua pada anak. Faktor psikologis anak dan orang tua (Huver, Otten, de Vries \& Engels, 2010; Prinzie dkk., 2004; Vafaeenejad dkk., 2019), serta faktor ekonomisosial (Belsky, 1984; Bradley \& Corwyn, 2002; Weinber, 2001; Yunus \& Dahlan, 2013) memiliki

*Fakultas Psikologi, Universitas Indonesia. Jl. Lingkar Kampus Raya, Pondok Cina, Beji, Depok. E-mail: inge.uliwiswanti@ui.ac.id 
pengaruh langsung dan spesifik pada praktek pola asuh sehari-hari yang ditunjukkan orang tua terhadap anaknya. Sedangkan, faktor perbedaan budaya memiliki pengaruh yang lebih luas, kompleks dan timbal balik terhadap pengasuhan (Bornstein, 2012; Dwairy dkk., 2006; Keshavarz \& Baharudin, 2009; Kuntoro, Peterson, \& Slaughter, 2017; Riany, Meredith, \& Cuskelly, 2017; Zevalkink \& Riksen-Walraven, 2001). Nilai-nilai budaya yang diwariskan antar generasi melebur dengan nilainilai yang ada di masyarakat sekitar tempat tinggal, akan membentuk penghayatan budaya yang berbeda pada orang tua dan memengaruhi praktek pengasuhan yang ditunjukkan sehari-hari. Di sisi lain, orang tua juga dapat memperkenalkan norma dan nilai-nilai budaya kepada anaknya lewat pengasuhan.

Penting untuk mengkaji lebih lanjut mengenai pengasuhan yang diterapkan orang tua dalam konteks budaya berbeda-beda, khususnya di Indonesia, negara kepulauan dengan 1.340 suku bangsa serta kebudayaan yang sangat beragam dan unik (Na'im \& Syaputra, 2010). Penelitian mengenai budaya dan gambaran pola asuh di Indonesia saat ini masih terbatas pada masyarakat Jawa (Mulder, 1992; Mulder, 2000), Sunda (French, Rianasari, Pidada, Nelwan \& Buhrmester, 2001; Kuntoro, Peterson, \& Slaughter, 2017; Zevalkink \& Riksen-Walvaren, 2001), Batak Karo (Kushnick, 2006), dan Minangkabau (RöttgerRössler, Scheidecker, Jung \& Holodynski, 2013). Penelitian-penelitian ini berfokus pada komparasi pola asuh masyarakat di wilayah-wilayah urban Indonesia atau dengan masyarakat di luar Indonesia, seperti: Amerika, Jepang, Belanda, dan Madagaskar.

Belum ditemukan studi komparasi antara pola asuh di masyarakat rural (yang kental nilai budaya tradisional) dengan masyarakat urban Indonesia (yang identik dengan modernisasi dan akulturasi budaya). Padahal masyarakat urban dan rural Indonesia memiliki dinamika budaya sendiri yang penting dan menarik untuk diteliti kaitannya dengan pola asuh. Terdapat perbedaan gaya hidup dan nilai-nilai yang dianggap penting antar masyarakat, yang dapat memengaruhi bagaimana orang tua di daerah urban dan rural Indonesia menerapkan pola pengasuhannya.

Penelitian ini memiliki unsur orisinalitas karena bertujuan untuk mengetahui gambaran perbedaan nilai budaya (konteks subkultur dalam negara) dan pola asuh antara masyarakat urban dengan masyarakat rural di Indonesia, yang belum pernah diteliti sebelumnya. Pertanyaan penelitian yang hendak dijawab adalah apakah terdapat perbedaan nilai budaya dan pola asuh antara masyarakat urban dengan masyarakat rural di Indonesia?

\section{Pola Asuh Masyarakat Urban dan Rural di Indonesia}

Vinden (2001) mengemukakan dua sikap pengasuhan yang sering ditunjukkan oleh orang tua, yaitu autonomy dan conformity, yang merefleksikan pola asuh otoritatif dan otoriter. Pola asuh otoritatif (autonomy) dan otoriter (conformity) diketahui dominan terlihat dalam pengasuhan sehari-hari orang tua terhadap anaknya di berbagai budaya (Vinden, 2001). Pola asuh otoritatif cenderung diterapkan masyarakat barat untuk membentuk kemandirian anaknya (Durgel, Vijver, \& Yagmurlu, 2012; Franke, Hofstede, \& Bond 1991); sedangkan, pola asuh otoriter ditunjukkan orang tua Asia untuk mengontrol perilaku anak di lingkungan sosial serta performa akademis anak (Keshavarz \& Baharudin, 2019; Rudy \& Grusec, 2001; Vinden, 2001; Xie \& Li, 2019). Lalu, bagaimana di Indonesia?

Mobilisasi sosial dan geografis serta akses pendidikan dan informasi yang lebih terbuka memungkinkan terjadinya globalisasi, yaitu pertukaran pandangan, pemikiran, dan aspek budaya lainnya, yang menyebabkan masyarakat urban Indonesia umumnya menerapkan gaya hidup dan pola pikir yang dipengaruhi oleh nilainilai dan kebiasaan yang ada di kota besar (Mulder, 2000). Hal ini kemudian dapat memengaruhi pola asuh orang tua urban. Orang tua di area metropolitan Jakarta (Jabodetabek)-area perkotaan dengan penduduk terpadat di Indonesia-cenderung terpengaruh oleh budaya barat dalam mengasuh dan menerapkan nilai budaya pada anaknya (Riany dkk., 2017).

Masyarakat barat menghayati budaya individualis yang menekankan kemandirian dan individualisme pada anggotanya (Triandis, 1994). Anak dianggap sebagai individu yang memiliki kemampuan, keterampilan, dan potensi di berbagai bidang yang perlu dikembangkan sejak dini. Pengasuhan otoritatif dianggap sebagai pola asuh yang efektif di budaya individualis (Durgel dkk., 2012; Franke, Hofstede, \& Bond 1991).

Penelitian Kuntoro, Peterson, dan Slaughter (2017) pada 122 ibu di area megapolitan Jakarta mengindikasikan bahwa 98\% ibu menganggap pola asuh otoritatif sebagai pola yang efektif dalam pengasuhan anaknya. Namun uniknya, para ibu tetap menghayati bahwa mereka adalah bagian dari masyarakat kolektif. Karakteristik partisipan yang sebagian besar (52\%) adalah ibu rumah tangga yang terbiasa untuk berkumpul dengan tetangga dan orang tua siswa di sekolah, tampaknya berkontribusi pada temuan yang unik ini. Hasil ini sejalan dengan penelitian Rau, McHale, dan Pearson (2003) pada orang tua di India. 
Nilai budaya kolektivisme, yang biasanya lebih banyak ditemui pada masyarakat timur, termasuk Asia, cenderung memberikan penekanan kuat pada hubungan yang harmonis dan interdependen dengan orang lain (Durgel dkk., 2012; Franke, Hofstede, \& Bond 1991). Budaya ini umumnya terlihat pada masyarakat rural di Indonesia, di antaranya masyarakat tradisional Jawa (Geertz, 1992; Mulder, 1992; Mulder, 2000) dan Minangkabau (Röttger-Rössler dkk., 2013). Jawa (95,2 juta jiwa) dan Minangkabau (6,5 juta jiwa) (Na'im \& Syaputra, 2010) merupakan dua suku di Indonesia yang sama-sama menekankan pentingnya tata karma serta kepatuhan dan rasa hormat pada orang tua.

Pada etnis Jawa tradisional, anak dituntut untuk mematuhi bimbingan dan arahan dari kedua orang tuanya (Mulder, 1992). Ayah memiliki peran dominan untuk menanamkan sopan santun dan disiplin pada anaknya agar dapat diterima dalam lingkungan sosial (Serad, 2012); di sisi lain, ibu cenderung berusaha menyediakan lingkungan yang aman dan penuh kasih sayang (Mulder, 1992; Zevalkink \& Riksen-Walraven, 2001). Keharmonisan adalah nilai yang sangat penting pada masyarakat Jawa tradisional, walau implementasinya bisa beragam pada setiap subkultur.

Koentjaraningrat (1994) membedakan etnis Jawa menjadi lima subkultur; dua diantaranya adalah Jawa Negarigung dan Jawa Mancanegari. Kedua subkultur ini memegang prinsip harmonis atau kerukunan, meskipun Jawa Mancanegari lebih terus terang dan terbuka dalam mengekspresikan pendapatnya dibanding Jawa Negarigung (Sartini, 2009; Sutarto, 2004). Masyarakat Jawa Negarigung lebih mengutamakan sikap dan perilaku unggah-ungguh, sedangkan Jawa Mancanegari lebih mementingkan kualitas hubungan dalam berelasi. Di sisi lain, masyarakat Minangkabau mengutamakan keterikatan interpersonal dalam hal pertimbangan pihak ketiga (alim ulama, cerdik pandai, dan ninik mamak) (Nashori dkk., 2020).

Pada masyarakat Minangkabau, pola asuh orang tua menekankan pada rasa saling menghargai dan sopan santun kepada orang yang lebih tua. Sopan santun ini berkaitan dengan rasa malu dan kontrol sosial yang ada di dalam masyarakat (Röttger-Rössler dkk., 2013). Saling menghargai bertujuan agar tercapai keharmonisan dalam pergaulan. Adat menyebutkan "nan tuo dihormati, samo gadang baok bakawan, nan ketek disayangi" yang berarti yang tua dihormati, sesama saling berkawan, yang muda disayangi (Amir, 2011; Diradjo, 2015).

Masyarakat Minangkabau juga dikenal sebagai masyarakat yang ekspresif dalam berpendapat, berani untuk tampil beda, serta demokratis atau terbuka terhadap ide dan opini baru selama tidak bertentangan dengan prinsip dasar agama Islam (Röttger-Rössler dkk., 2013). Dalam mengambil keputusan, cara yang diutamakan umumnya adalah konsensus dan mufakat atau "bulek kato dek mufakat" yang mana dalam Bahasa Indonesia "bulat kata karena mufakat" (Chandra, 2004). Anak diberi kesempatan untuk menjadi kritis dan berani mengambil keputusan, serta bertanggung jawab atasnya. Pendidikan menjadi hal yang penting bagi masyarakat Minangkabau.

Dari penjabaran di atas, terlihat nilai kolektivisme dan individualisme dihayati secara padu oleh masyarakat urban (Kuntoro dkk., 2017; Rau dkk., 2003) serta masyarakat Minangkabau dan Jawa tradisional (rural). Kedua nilai budaya ini nyatanya tidak dihayati secara eksklusif oleh masyarakat rural maupun urban di Indonesia; tidak selalu budaya kolektivisme menjadi milik masyarakat rural saja, dan budaya individualisme hanya milik masyarakat urban. Oleh sebab itu, perlu dipahami bahwa perbandingan kolektivisme dan individualisme pada masyarakat urban dan rural dapat bervariasi antar budaya, yang mengakibatkan munculnya perbedaan praktek pengasuhan yang mendominasi antar masyarakat dengan budaya berbeda. Hal ini mengarahkan hipotesis penelitian sebagai berikut:

\section{Untuk penghayatan nilai budaya}

Ho: Terdapat perbedaan penghayatan nilai budaya antara masyarakat urban dengan masyarakat rural Jawa dan Minangkabau di Indonesia.

Ha: Tidak terdapat perbedaan penghayatan nilai budaya antara masyarakat urban dengan masyarakat rural Jawa dan Minangkabau di Indonesia.

\section{Untuk pengasuhan orang tua}

Ho: Terdapat perbedaan pola pengasuhan sehari-hari antara orang tua urban dengan orang tua rural Jawa dan Minangkabau di Indonesia.

Ha: Tidak terdapat perbedaan pola pengasuhan sehari-hari antara orang tua urban dengan orang tua rural Jawa dan Minangkabau di Indonesia.

Peneliti mengontrol beberapa variabel kovariat yang secara teoritis juga dapat memengaruhi pola pengasuhan orang tua terhadap anak, yaitu: usia anak (Papalia dkk., 2007), usia ayah dan ibu, pekerjaan, serta pendidikan ayah dan ibu (Belsky, 1984; Bradley \& Corwyn, 2002; Weinber, 2001; Yunus \& Dahlan, 2013). Kontrol perlu dilakukan terhadap variabel-variabel ini agar didapatkan gambaran yang lebih jelas dan 
presisi tentang perbedaan nilai budaya dan pola pengasuhan orang tua antara wilayah Jabodetabek (urban) serta Magelang dan Bukittinggi (rural).

\section{Metode Penelitian}

\section{Partisipan Penelitian}

Karena penelitian ini bertujuan untuk mengeksplorasi perbedaan budaya dan pola asuh pada populasi yang sangat besar (masyarakat urban dan rural Indonesia), maka digunakan teknik convenience sampling yang berfokus pada efektivitas biaya, efisiensi waktu, serta kemudahan akses dalam merekrut partisipan. Partisipan untuk masyarakat urban adalah ibu yang tinggal di area metropolitan Jakarta, meliputi DKI Jakarta, Bogor, Bekasi, dan Tangerang (Yamashita, 2017). Sedangkan untuk masyarakat rural adalah ibu bersuku Jawa yang tinggal di wilayah Magelang, serta orang tua bersuku Minangkabau yang tinggal di wilayah Bukittinggi. Identitas partisipan yang terlibat dalam penelitian ini terjamin kerahasiaannya. Dari proses sampling, diperoleh 383 partisipan yang memenuhi persyaratan dengan rincian: partisipan urban Jabodetabek ( $\mathrm{N}$ = 204), partisipan rural Magelang dan sekitarnya $(\mathrm{N}=101)$, serta partisipan rural Bukittinggi $(\mathrm{N}=$ 78). Gambaran detil partisipan penelitian dapat dilihat pada Tabel 1. Partisipan yang memenuhi persyaratan dan mengisi kuesioner secara lengkap sampai akhir mendapatkan voucher atau pulsa elektronik senilai Rp 50.000,00.

\section{Desain Penelitian}

Penelitian ini menggunakan pendekatan kuantitatif karena variabel yang diteliti dapat menerangkan fenomena pada masyarakat luas serta diperlukan uji hipotesis untuk mengetahui perbedaan nilai budaya dan pola asuh antar masyarakat. Desain penelitian ini adalah desain komparatif deskriptif (mean comparation), yaitu membandingkan variabel yang sama pada kelompok yang berbeda. Dalam penelitian ini, variabel yang akan dibandingkan adalah nilai budaya (kolektivisme dan individualisme) serta pola asuh orang tua (conformity dan autonomy) antara kelompok masyarakat urban dengan rural. Nantinya kelompok masyarakat urban dan rural ini akan dibagi menjadi tiga kelompok wilayah yakni Jabodetabek (urban), Magelang (rural), dan Bukittinggi (rural). Hasil luaran yang diharapkan dari penelitian ini adalah gambaran mengenai perbedaan penghayatan antara masyarakat urban dan rural terhadap nilai budaya yang diyakini dan nilai pengasuhan yang diterapkan seharihari. Desain ini selaras dengan tujuan penelitian. Prosedur Penelitian

Data dikumpulkan secara daring dan luring untuk partisipan di wilayah urban (Jabodetabek) lewat aplikasi Typeform serta kunjungan ke taman kanak-kanak dan sekolah dasar di daerah Jabodetabek. Sedangkan data untuk wilayah rural dikumpulkan secara luring; di satu sekolah dasar swasta berbasis agama di Magelang dan dua taman kanak-kanak swasta di Bukittinggi. Hal ini berkaitan dengan terbatasnya jumlah partisipan yang mengisi kuesioner sampai selesai secara daring; dari \pm 200 partisipan yang berkunjung ke tautan Typeform, hanya seperlimanya yang selesai mengerjakan kuesioner. Undangan untuk berpartisipasi secara daring sudah dikirimkan lewat jejaring sosial Facebook, Whatsapp, dan Instagram dengan menyertakan tautan pengisian kuesioner. Oleh sebab itu, dilakukan upaya lain dalam mengumpulkan data yaitu dengan mengunjungi langsung sekolah-sekolah untuk proses pengisian kuesioner secara luring.

Seluruh partisipan mendapatkan informasi umum mengenai penelitian ini (informed consent) di awal survei, baik daring maupun luring. Partisipan kemudian diminta untuk memberi tanda $(\sqrt{ })$ pada kolom "Setuju", sebelum mulai mengisi kuesioner, untuk menyatakan kesediaannya berpartisipasi dalam penelitian ini.

\section{Alat Ukur Penelitian}

Alat ukur dalam penelitian ini berupa dua buah self-report inventory. Skala pertama, yaitu PAI 1, mengukur preferensi orang tua terhadap budaya kolektivisme dan individualisme, yang diadaptasi dari skala untuk orang dewasa yang belum menjadi orang tua yang dikembangkan oleh Triandis dan Gelfand (1998). Skala ini diadaptasi oleh Kuntoro dkk. (2017) dalam penelitiannya di Indonesia. Terdapat 16 item yang disesuaikan dengan konteks pengasuhan orang tua, delapan item mengenai budaya individualisme dan delapan item untuk budaya kolektivisme. Contoh item untuk budaya kolektivisme adalah "Anak saya harus menomorsatukan acara/kegiatan keluarga" dan "Anak saya harus rukun dengan saudara dan teman-temannya." Untuk contoh item budaya individualisme adalah "Saya ingin anak saya terlihat unik (menonjol) dan berbeda dari anak lain" dan "Anak saya harus selalu menjadi juara di kelas atau menang dalam perlombaan." Setiap item terdiri dari pernyataan yang harus direspon orang tua dengan menggunakan 5-poin skala: 5 = sangat setuju, $4=$ agak setuju, 3 = netral, 2 = agak tidak setuju dan $1=$ 
sangat tidak setuju. Skor reliabilitas dengan Cronbach's Alpha menunjukkan nilai $\alpha=.733$ untuk kolektivisme dan $\alpha=.718$ untuk individualisme, artinya alat ukur ini memiliki internal konsistensi yang baik antar item.

Skala kedua, yaitu PAI 2, mengadaptasi Parenting Attitudes Inventory (PAI) yang disusun oleh Vinden (2001), lalu dikembangkan oleh O'Reilly \& Peterson (2014). Dalam penelitian ini, akan digunakan skala PAI dari O'Reilly dan Peterson yang telah mengatasi keterbatasan metodologis yang terdapat di versi asli milik Vinden. Skala ini terdiri dari dua sub-skala (conformity vs autonomy) dengan masing-masing terdiri dari enam item. Conformity mengukur pola asuh otoriter, serta autonomy mengukur pola asuh otoritatif. Contoh item conformity yang diberikan adalah "Anak saya harus mematuhi aturan yang diberikan orang tua" dan "Anak saya harus setuju dengan pendapat dan perkataan saya." Untuk contoh item autonomy adalah "Anak saya boleh membuat keputusan sendiri tanpa mendapat persetujuan orang tua" dan "Anak saya boleh memiliki pendapat yang berbeda/bertentangan dengan pendapat orang tuanya." Untuk mencegah respon yang terpola, maka item-item conformity akan diselingi oleh item-item auto-nomy. Respon menggunakan 5-poin skala seperti PAI 1. Skor reliabilitas dengan Cronbach's Alpha menunjukkan nilai $\alpha=.850$ untuk conformity dan $\alpha=.731$ untuk autonomy, yang berarti alat ukur ini memiliki internal konsistensi yang baik antar item.

\section{Teknik Analisis Data}

Teknik analisis data yang digunakan dalam penelitian ini adalah independent $t$-test dan one-way Analysis of Variance (ANOVA). Untuk analisis lebih lanjut akan dilakukan dengan post hoc test with ANOVA dan Analysis of Covariance (ANCOVA).

Independent t-test digunakan untuk menguji signifikansi perbedaan rata-rata dua kondisi/variabel antar dua kelompok partisipan (Field, 2005). Variabel yang diuji adalah nilai budaya serta pola asuh antar kelompok urban dan rural. Perhitungan one-way ANOVA kemudian dilakukan untuk menguji perbedaan rata-rata antar tiga kelompok atau lebih (Field, 2005), yaitu: kelompok Jabodetabek (representasi urban), serta Magelang dan Bukittinggi (representasi rural). Lebih lanjut, post hoc test with ANOVA dilakukan untuk menganalisis perbedaan nilai budaya dan pola pengasuhan di masing-masing wilayah. Terakhir, ANCOVA dilakukan untuk menguji signifikansi perbedaan rata-rata variabel nilai budaya dan pola asuh di tiga wilayah, dengan mengontrol efek dari variabel lain (covariates) yang diprediksi secara teoritis dapat memengaruhi hasil pengujian.

\section{Hasil Penelitian}

\section{Gambaran Umum Partisipan}

Total partisipan dalam penelitian ini adalah 403 orang; sebanyak 20 orang di-exclude karena data yang tidak lengkap dan partisipan tidak memenuhi kriteria (salah satu orang tua meninggal), sehingga data akhir yang diolah adalah 383 orang. Tabel 1 menampilkan gambaran komprehensif dari partisipan penelitian.

Rata-rata ayah dan ibu berpendidikan Diploma 3 (31,9\%). Mayoritas ibu dalam penelitian ini adalah ibu rumah tangga $(56,4 \%)$, dan sebagian besar ayah bekerja pada tingkat skilled job dan staf misalnya tentara dan pegawai swasta pada level manajer ke bawah $(49,9 \%)$. Rentang usia ayah adalah 27-64 tahun $(\mathrm{M}=39,33$; $\mathrm{SD}=$ $5,86)$ dan ibu 23-53 tahun ( $M=36,07 ; S D=5,21$ ). Orang tua memiliki setidaknya satu orang anak yang berusia di rentang 5-12 tahun. Pada usia ini, orang tua umumnya secara aktif menanamkan nilai-nilai dan norma yang berdampak pada pembentukan konsep diri, kepercayaan diri, pemahaman akan harapan sosial, perilaku sosial dan keyakinan akan kemampuan yang dimiliki pada anak (Papalia dkk., 2007).

\section{Komparasi Masyarakat Urban dan Rural}

Berdasarkan Tabel 1, terlihat bahwa perbandingan antara partisipan rural dan urban cukup seimbang 53,3\% dan 46,7\%. Peneliti pun membandingkan bagaimana masyarakat urban dan rural menghayati nilai budaya yang diyakini dan pola asuh yang diterapkan sehari-hari, menggunakan independent sample t-test (Tabel 2). Terlebih dahulu dilakukan uji normalitas Kolmogorov-Smirnov dan uji varians Levene's test dengan hasil data terdistribusi normal dan persebaran variannya setara antar masing-masing kelompok.

Tabel 2 menunjukkan adanya perbedaan yang signifikan antara nilai budaya dan pola asuh pada kelompok rural dan urban. Perbedaan paling menonjol terlihat pada PAI 2 dimensi conformity; kelompok urban $(M=12,73$; $S D=43,56)$ lebih rendah mean skornya sebesar 8,67 dibandingkan kelompok rural $(\mathrm{M}=21,4 ; \mathrm{SD}=3,34) ; \mathrm{t}(381)=$ $24,51, \mathrm{p}<0,001$. Begitu pula dengan dimensi autonomy, di mana rata-rata skor kelompok urban (M $=23,71 ; \mathrm{SD}=3,07$ ) lebih tinggi 4,10 dibanding kelompok rural $(\mathrm{M}=19,7 ; \mathrm{SD}=4,06) ; \mathrm{t}(381)=$ $10,99, \mathrm{p}<0,001$. 
Tabel 1.

Gambaran Partisipan Penelitian

\begin{tabular}{|c|c|c|c|c|c|}
\hline Karakteristik & & Jumlah (n) & Persen (\%) & Means & $S D$ \\
\hline \multirow[t]{2}{*}{ Daerah } & Urban & 204 & 53,3 & & \\
\hline & Rural & 179 & 46,7 & & \\
\hline \multirow[t]{3}{*}{ Kota } & Jabodetabek & 204 & 53,3 & & \\
\hline & Magelang, dsk & 101 & 26,4 & & \\
\hline & Bukittinggi & 78 & 20,3 & & \\
\hline \multirow[t]{7}{*}{ Usia Anak } & $46-60$ bulan & 50 & 13 & 84,9 & 28,6 \\
\hline & $61-75$ bulan & 173 & 45,2 & & \\
\hline & 76 - 90 bulan & 58 & 15,1 & & \\
\hline & $105-120$ bulan & 24 & 6,3 & & \\
\hline & 121 - 135 bulan & 44 & 11,5 & & \\
\hline & $136-150$ bulan & 33 & 8,6 & & \\
\hline & $>150$ bulan & 1 & 0,3 & & \\
\hline \multirow[t]{4}{*}{ Usia Ayah } & 26-30 tahun & 16 & 4,2 & 39,33 & 5,86 \\
\hline & 31-35 tahun & 88 & 23 & & \\
\hline & 36-40 tahun & 128 & 33,4 & & \\
\hline & $>41$ tahun & 151 & 39 & & \\
\hline \multirow[t]{5}{*}{ Usia Ibu } & $>25$ tahun & 4 & 1 & 36,07 & 5,21 \\
\hline & 26-30 tahun & 49 & 12,8 & & \\
\hline & 31-35 tahun & 136 & 35,5 & & \\
\hline & 36-40 tahun & 136 & 35,5 & & \\
\hline & $>41$ tahun & 58 & 15,1 & & \\
\hline \multirow[t]{7}{*}{ Pendidikan Ayah } & SD & 7 & 1,8 & & \\
\hline & SMP & 65 & 17 & & \\
\hline & SMA & 107 & 27,9 & & \\
\hline & D3 & 122 & 31,9 & & \\
\hline & $\mathrm{S} 1$ & 67 & 17,5 & & \\
\hline & $\mathrm{S} 2$ & 14 & 3,7 & & \\
\hline & S3 & 1 & 0,3 & & \\
\hline \multirow[t]{6}{*}{ Pendidikan Ibu } & SD & 5 & 1,8 & & \\
\hline & SMP & 87 & 17 & & \\
\hline & SMA & 84 & 27,9 & & \\
\hline & D3 & 130 & 31,9 & & \\
\hline & $\mathrm{S} 1$ & 66 & 17,5 & & \\
\hline & $\mathrm{S} 2$ & 11 & 3,7 & & \\
\hline \multirow[t]{5}{*}{ Pekerjaan Ayah* } & 1 & 62 & 16,2 & & \\
\hline & 2 & 39 & 7,6 & & \\
\hline & 3 & 191 & 49,9 & & \\
\hline & 4 & 43 & 11,2 & & \\
\hline & 5 & 58 & 15,1 & & \\
\hline \multirow[t]{5}{*}{ Pekerjaan Ibu** } & 1 & 216 & 56,4 & & \\
\hline & 2 & 7 & 1,8 & & \\
\hline & 3 & 92 & 24,0 & & \\
\hline & 4 & 39 & 10,2 & & \\
\hline & 5 & 29 & 7,6 & & \\
\hline
\end{tabular}

*1: unskilled occupation dan pensiunan 2: Semi-skilled occupation 3: Skilled occupation 4: Managerial \& Staffs; 5: Pejabat, Profesional, Ahli ** 1: unskilled occupation dan ibu rumah tangga 2: Semi-skilled occupation 3: Skilled occupation dan Staf 4: Managerial \& Karir; 5: Pejabat, Profesional, Ahli.

Dimensi individualisme pada PAI 1 menunjukkan hasil yang secara signifikan berbeda antara rural dan urban; $\mathrm{t}(381)=2,28$; $\mathrm{p}<0,05$, di mana kelompok urban $(\mathrm{M}=23,7 ; \mathrm{SD}=4,46)$ lebih tinggi dibandingkan rural $(\mathrm{M}=22,69 ; \mathrm{SD}=4,17)$ dengan selisih mean skor 1,01. Dimensi kolektivisme juga signifikan berbeda di kelompok urban dan rural $(\mathrm{t}(381)=8,475, \mathrm{p}<0,001)$, di mana mean 
urban $(\mathrm{M}=31,37 ; \mathrm{SD}=3,8)$ lebih tinggi sebesar 3,58 dibandingkan kelompok rural ( $M=27,79$; $S D$ $=4,46)$.

\section{Komparasi Masyarakat Urban dan Rural}

Berdasarkan Tabel 1, terlihat bahwa perbandingan antara partisipan rural dan urban cukup seimbang 53,3\% dan 46,7\%. Peneliti pun membandingkan bagaimana masyarakat urban dan rural menghayati nilai budaya yang diyakini dan pola asuh yang diterapkan sehari-hari, menggunakan independent sample t-test (Tabel 2). Terlebih dahulu dilakukan uji normalitas Kolmogorov-Smirnov dan uji varians Levene's test dengan hasil data terdistribusi normal dan persebaran variannya setara antar masing-masing kelompok. Tabel 2 menunjukkan adanya perbedaan yang signifikan antara nilai budaya dan pola asuh pada kelompok rural dan urban. Perbedaan paling menonjol terlihat pada PAI 2 dimensi conformity; kelompok urban ( $\mathrm{M}=12,73$; $\mathrm{SD}=43,56)$ lebih rendah mean skornya sebesar 8,67 dibandingkan kelompok rural $(\mathrm{M}=21,4 ; \mathrm{SD}=3,34)$; $\mathrm{t}(381)=-24,51, \mathrm{p}<0,001$. Begitu pula dengan dimensi autonomy, di mana rata-rata skor kelompok urban $(M=23,71 ; S D=3,07)$ lebih tinggi 4,10 dibanding kelompok rural $(\mathrm{M}=19,7 ; \mathrm{SD}=4,06)$; $\mathrm{t}(381)=10,99, \mathrm{p}<0,001$. Dimensi individualisme pada PAI 1 menunjukkan hasil yang secara signifikan berbeda antara rural dan urban; $\mathrm{t}(381)=$ 2,28; $\mathrm{p}<0,05$, di mana kelompok urban $(\mathrm{M}=23,7$; $\mathrm{SD}=4,46)$ lebih tinggi dibandingkan rural $(\mathrm{M}=$ 22,69; $\mathrm{SD}=4,17$ ) dengan selisih mean skor 1,01. Dimensi kolektivisme juga signifikan berbeda di kelompok urban dan rural $(\mathrm{t}(381)=8,475$, $\mathrm{p}<0,001)$, di mana mean urban $(\mathrm{M}=31,37 ; \mathrm{SD}=$ 3,8) lebih tinggi sebesar 3,58 dibandingkan kelompok rural $(M=27,79 ; \mathrm{SD}=4,46)$.

\section{Komparasi Masyarakat Jabodetabek, Magelang, dan Bukittinggi}

Peneliti kemudian membagi kelompok rural menjadi wilayah Magelang dan Bukittinggi, serta kelompok urban direpresentasikan oleh wilayah Jabodetabek sehingga terdapat tiga kelompok wilayah dalam penelitian ini yang dianalisis menggunakan one-way ANOVA. Hasil perbandingan rata-rata tiga wilayah per dimensi ditunjukkan menggunakan grafik pada Gambar 1 . Untuk melihat perbandingan masing-masing wilayah dilakukan analisis post-hoc Tukey (Tabel 3). Uji normalitas dan homogenitas dilakukan terlebih dahulu dengan hasil persebaran data normal dan homogen pada tiga kelompok wilayah.

Hasil one-way ANOVA menunjukkan bahwa tiga dari empat dimensi PAI 1 (kolektivisme) serta PAI 2 (conformity dan autonomy) secara signifikan berbeda di masing-masing wilayah. Dimensi nilai budaya kolektivisme secara signifikan berbeda di setiap wilayah $\mathrm{F}(2,380)=101,77$; $\mathrm{p}<0,0001$; partial $\eta 20,349$, lebih jauh analisis post hoc Tukey menunjukkan bahwa Magelang $(M=30,31 ; S D=3,71)$ secara signifikan lebih tinggi skornya $(\mathrm{p}<0,001)$ dibandingkan Bukittinggi $(M=24,54$; $S D=3,02)$ dan secara signifikan lebih rendah $(\mathrm{p}=0,043)$ dari Jabodetabek (M $=31,37 ; \mathrm{SD}=3,8)$. Wilayah Bukittinggi secara signifikan lebih rendah dibandingkan kedua wilayah lain $(p<0,001)$ dan Jabodetabek secara signifikan lebih tinggi $(p=0,43)$ dibandingkan Magelang dan Bukittinggi $(\mathrm{p}<0,001)$.

Dimensi conformity secara signifikan berbeda di setiap wilayah $\mathrm{F}(2,380)=343,52$; $\mathrm{p}<0,0001$; partial $\eta 20,644$. Analisis post hoc Tukey menunjukkan bahwa Magelang $(M=22,67$; $\mathrm{SD}=3,21$ ) secara signifikan lebih tinggi skornya dibandingkan Bukittinggi $(M=19,76 ; S D=2,75)$ dan dari Jabodetabek $(M=12,73$; $S D=3,56)$ dengan $\mathrm{p}<0,001$ untuk keduanya. Bukittinggi secara signifikan lebih rendah dibandingkan Jawa tetapi lebih tinggi jika dibandingkan Jabodetabek $(\mathrm{p}<0,001)$. Lain halnya dengan Jabodetabek yang secara signifikan lebih rendah rata-ratanya jika dibandingkan Magelang dan Bukittinggi $(\mathrm{p}<0,001)$.

Dimensi autonomy juga menunjukkan hasil yang signifikan berbeda di setiap wilayah $\mathrm{F}$ $(2,380)=173,24 ; \mathrm{p}<0,0001 ;$ partial $\eta 2$ 0,477. Hasil dari analisis post-hoc Tukey menunjukkan bahwa Jabodetabek $(M=23,71 ; \mathrm{SD}=3,07)$ secara signifikan lebih tinggi skornya $(\mathrm{p}<0,001)$ jika dibandingkan dengan Bukittinggi $(\mathrm{M}=16,4 ; \mathrm{SD}=$ $2,64)$ dan Magelang ( $M=22,25 ; S D=2,98)$. Wilayah Bukittinggi secara signifikan lebih rendah dari dua wilayah lainnya $(\mathrm{p}<0,001)$ dan Magelang secara signifikan lebih tinggi dari Bukittinggi tetapi lebih rendah dari Jabodetabek. Sedangkan dimensi individualisme tidak signifikan berbeda di ketiga wilayah $F(2,380)=2,70 ; p=0,068$; partial $\eta 20,014$.

Lebih jauh lagi, peneliti melakukan analisis ANCOVA dengan mengontrol tujuh variabel dari data demografis (usia anak, usia ayah, usia ibu, pendidikan ayah, pendidikan ibu, pekerjaan ayah, dan pekerjaan ibu). Setelah dilakukan kontrol, dimensi individualisme PAI 1 menunjukkan hasil yang signifikan berbeda pada tiga wilayah penelitian $(F(9,373)=6,485 ; p=0,002$; partial $\eta 2$ 0,034. Dimensi kolektivisme PAI 1 pun secara signifikan berbeda di setiap wilayah F (9, 373 ) =60,448; p<0,0001; partial $\eta 2$ 0,245. Pada PAI 2, dimensi autonomy menunjukkan hasil yang signifikan berbeda di setiap wilayah $F(9,373)=$ 81,955; $p<0,0001$; partial $\eta 2$ 0,305; begitu juga dimensi conformity juga hasilnya berbeda secara signifikan di setiap wilayah F $(9,373)=58,920$; p $<0,0001$; partial $\eta 20,240$. 
Tabel 2.

Hasil Analisis Independent sample t-test Antara Sampel Urban dan Rural untuk Setiap Variabel $(N=383)$

\begin{tabular}{|c|c|c|c|c|c|c|}
\hline \multirow{3}{*}{ Variabe } & & \multicolumn{4}{|c|}{ Wilayah } & \multirow{3}{*}{$t$} \\
\hline & & \multicolumn{2}{|c|}{ Urban ( $n=204)$} & \multicolumn{2}{|c|}{ Rural ( $n=179)$} & \\
\hline & & Means & $S D$ & Means & $S D$ & \\
\hline \multirow[t]{2}{*}{ PAI 1} & Individualisme & 23,7 & 4,46 & 22,69 & 4,17 & $2,28^{*}$ \\
\hline & Kolektivisme & 31,37 & 3,80 & 27,79 & 4,46 & $8,475^{* * *}$ \\
\hline \multirow[t]{2}{*}{ PAI 2} & Conformity & 12,73 & 3,56 & 21,4 & 3,34 & $-24,51 * * *$ \\
\hline & Autonomy & 23,71 & 3,07 & 19,7 & 4,06 & $10,99 * * *$ \\
\hline
\end{tabular}

*** $\mathrm{p}<0,001 ;{ }^{* *} \mathrm{p}<0,01 ; \mathrm{p}<0,05$

Gambar 1.

Rata-rata dari dua dimensi PAI 1 (Individualisme dan Kolektivisme) serta PAI 2 (Conformity dan Autonomy) di tiga wilayah yakni Magelang, Bukittinggi, dan Jabodetabek. Error bars pada grafik adalah standar error (SE).
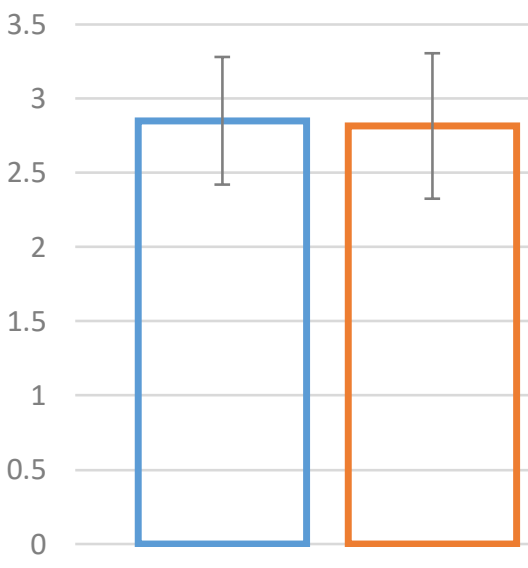

Individualis

口 Magelang

口Bukittinggi aJabodetabek

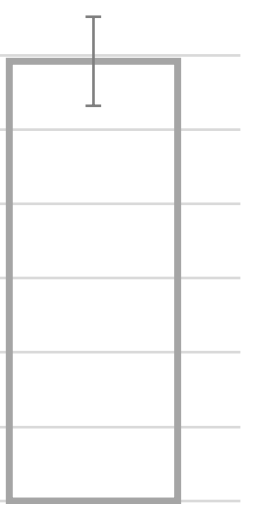

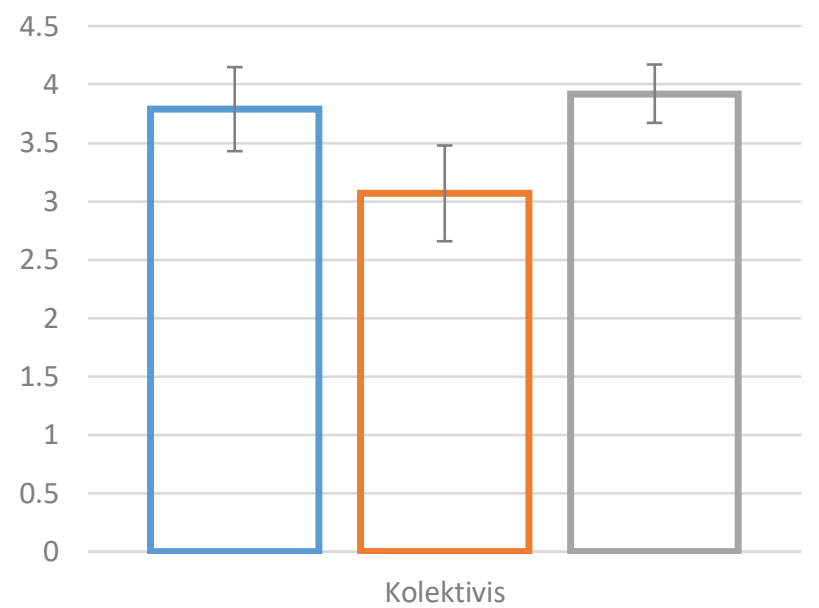

- Magelang

Dabodetabek

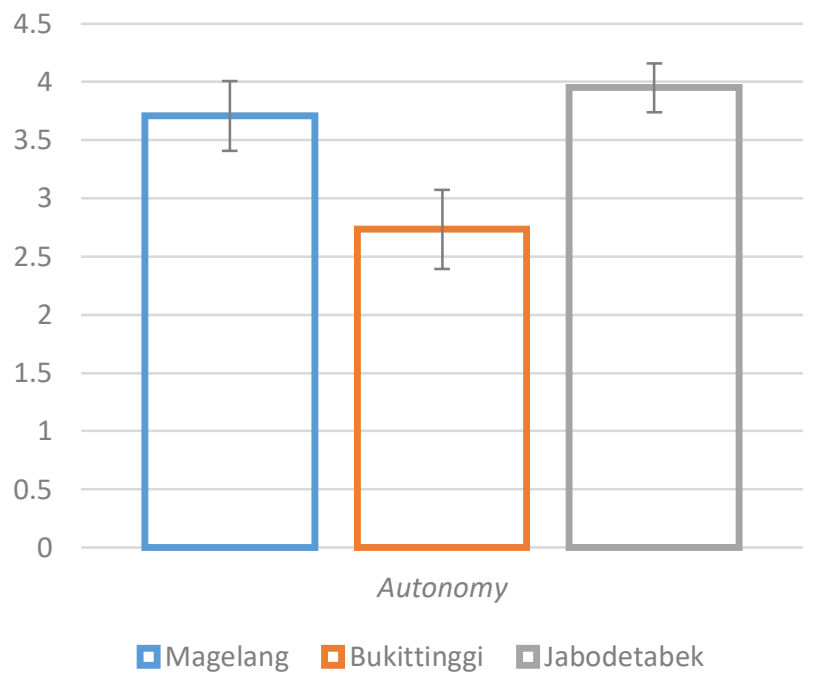


Tabel 3.

Hasil Post-Hoc Antara Kelompok Jabodetabek Magelang dan Bukittinggi dengan Pengasuhan

\begin{tabular}{|c|c|c|c|c|c|}
\hline \multirow[b]{2}{*}{ Variabel } & \multirow[b]{2}{*}{ (I) Wilayah } & \multicolumn{4}{|c|}{ Perbedaan } \\
\hline & & (J) Wilayah & Rerata (I-J) & SE & $p$ \\
\hline \multirow[t]{6}{*}{ Individualisme } & \multirow[t]{2}{*}{ Magelang } & Bukittinggi & ,29 & 650 & 899 \\
\hline & & Jabodetabek &,- 88 &, 525 & ,212 \\
\hline & \multirow[t]{2}{*}{ Bukittinggi } & Magelang &,- 29 & ,650 & ,899 \\
\hline & & Jabodetabek & $-1,17$ & ,574 & 104 \\
\hline & \multirow[t]{2}{*}{ Jabodetabek } & Magelang & ,88 & ,525 & ,212 \\
\hline & & Bukittinggi & 1,17 &, 574 & ,104 \\
\hline \multirow[t]{6}{*}{ Kolektivisme } & \multirow[t]{2}{*}{ Magelang } & Bukittinggi & $5,77^{*}$ & ,548 & 000 \\
\hline & & Jabodetabek & $-1,07^{*}$ & ,442 & ,043 \\
\hline & \multirow[t]{2}{*}{ Bukittinggi } & Magelang & $-5,77^{*}$ & ,548 & ,000 \\
\hline & & Jabodetabek & $-6,83^{*}$ & ,484 & 000 \\
\hline & \multirow[t]{2}{*}{ Jabodetabek } & Magelang & $1,07^{*}$ & ,442 & ,043 \\
\hline & & Bukittinggi & $6,83^{*}$ & ,484 &, 000 \\
\hline \multirow[t]{6}{*}{ Conformity } & \multirow[t]{2}{*}{ Magelang } & Bukittinggi & $2,92^{*}$ &, 500 & 000 \\
\hline & & Jabodetabek & $9,95^{*}$ & 403 & 000 \\
\hline & \multirow[t]{2}{*}{ Bukittinggi } & Magelang & $-2,92^{*}$ & ,500 & 000 \\
\hline & & Jabodetabek & $7,03^{*}$ & ,441 & 000 \\
\hline & \multirow[t]{2}{*}{ Jabodetabek } & Magelang & $-9,95^{*}$ & ,403 & 000 \\
\hline & & Bukittinggi & $-7,03^{*}$ & ,441 &, 000 \\
\hline \multirow[t]{6}{*}{ Autonomy } & \multirow[t]{2}{*}{ Magelang } & Bukittinggi & $5,85^{*}$ & ,447 & 000 \\
\hline & & Jabodetabek & $-1,46^{*}$ & ,360 & 000 \\
\hline & \multirow[t]{2}{*}{ Bukittinggi } & Magelang dsk & $-5,85^{*}$ & ,447 & ,000 \\
\hline & & Jabodetabek & $-7,31^{*}$ & ,394 & 000 \\
\hline & \multirow[t]{2}{*}{ Jabodetabek } & Magelang & $1,46^{*}$ & ,360 & ,000 \\
\hline & & Minangkabau & $7,31^{*}$ & ,394 &, 000 \\
\hline
\end{tabular}

\section{Diskusi}

Penelitian ini bertujuan untuk mengetahui gambaran perbedaan nilai budaya dan pola asuh antara masyarakat urban dengan masyarakat rural di Indonesia. Hasil penelitian secara umum menunjukkan bahwa terdapat perbedaan yang signifikan antara nilai budaya dan pola pengasuhan pada kelompok urban dan rural di Indonesia. Hal ini berarti Ho penelitian ini diterima.

Penghayatan nilai budaya kolektivisme dan individualisme lebih terlihat pada kelompok masyarakat urban dibandingkan rural. Untuk dimensi pengasuhan, kelompok masyarakat rural lebih menunjukkan sikap conformity sedangkan urban lebih autonomy. Masyarakat rural masih dominan memegang budaya ketimuran yang menekankan pada pentingnya hubungan yang harmonis dan interdependen dengan orang lain (nilai kolektivisme) sehingga pola pengasuhan yang diterapkan pun cenderung mengarahkan anak untuk mengontrol perilaku (conformity) agar dapat diterima di lingkungan dengan baik (Keshavarz \& Baharudin, 2019; Rudy \& Grusec, 2001; Vinden, 2001).

Sedangkan seperti yang dikemukakan oleh Riany dkk. (2017), orang tua urban-area metropolitan Jakarta (Jabodetabek)-banyak terpengaruh oleh budaya barat yang individualis sehingga berimbas pada pengasuhan sehari-hari yang cenderung autonomy; orang tua menekankan pada kemandirian dan individualisme anak (Triandis, 1994). Ini dapat disebabkan mobilisasi sosial serta akses informasi yang lebih terbuka sehingga memungkinkan terjadinya globalisasi dan pertukaran informasi yang memengaruhi gaya hidup dan pola pikir masyarakat urban (Mulder, 2000). Namun uniknya dalam penelitian ini, selain nilai budaya individualisme, partisipan urban juga menghayati nilai budaya kolektivisme dalam keseharian mereka. Hal ini menegaskan bahwa kedua nilai budaya ini tidak bersifat eksklusif dan dapat dihayati secara padu oleh masyarakat urban.

Tiga kelompok wilayah, yaitu: Jabodetabek (urban), Magelang (Jawa rural) dan Bukittinggi (Minangkabau rural), kemudian ditelaah lebih lanjut. Peneliti menemukan bahwa nilai budaya kolektivisme serta sikap pengasuhan conformity dan autonomy berbeda secara signifikan di masing-masing wilayah, sedangkan nilai budaya individualisme tidak menunjukkan perbedaan yang signifikan di ketiga wilayah. Berikut adalah hasil temuan yang penting antar 
wilayah: (1) partisipan Jabodetabek menunjukkan penghayatan nilai budaya kolektivisme yang lebih tinggi dibandingkan Magelang dan Bukittinggi; (2) partisipan Magelang menunjukkan pengasuhan conformity yang lebih tinggi dibandingkan Bukittinggi dan Jabodetabek; dan (3) partisipan Jabodetabek menunjukkan pengasuhan autonomy yang lebih tinggi dibandingkan Magelang dan Bukittinggi.

Ketika dibandingkan dengan masingmasing budaya, ditemukan hasil yang unik, yaitu orang tua Jabodetabek lebih menghayati budaya kolektivisme dalam hidup mereka dibandingkan orang tua Jawa dan Minangkabau, meskipun tetap menerapkan pengasuhan autonomy di kesehariannya. Orang tua menunjukkan keterbukaan untuk berdiskusi dengan anaknya, misalnya: dalam menetapkan peraturan rumah yang disepakati bersama serta mengajarkan nilai-nilai kehidupan kepada anaknya, sambil tetap mengajarkan tata karma dan pentingnya menjaga hubungan baik dengan keluarga dan teman. Hasil ini sejalan dengan penelitian Rau dkk. (2003) dan Kuntoro dkk. (2017). Partisipan yang sebagian besar adalah ibu rumah tangga $(56,4 \%)$ serta proporsi jumlah partisipan yang kurang berimbang; Jabodetabek 53,3\% ( $\mathrm{N}=204)$, Magelang $26,4 \%(N=101)$ dan Bukittinggi 20,3\% ( $=78)$ tampaknya berkontribusi terhadap hasil ini.

Sejalan dengan hasil uji hipotesis, partisipan Magelang (Jawa) dan Bukittinggi (Minangkabau) yang adalah representasi dari masyarakat rural menunjukkan pengasuhan conformity (otoriter) yang lebih dominan dibandingkan partisipan Jabodetabek. Partisipan Jawa dan Minangkabau sama-sama menekankan pentingnya tata karma serta kepatuhan dan rasa hormat pada orang tua.

Pada partisipan Magelang (Jawa), pengasuhan conformity $(\mathrm{M}=22,67)$ dan autonomy ( $\mathrm{M}$ $=22,25$ ) berimbang. Ini mengindikasikan bahwa latar belakang pekerjaan orang tua (ayah) memiliki pengaruh yang juga kuat, selain nilai budaya atau cara hidup yang orang tua pegang. Sebagian besar ayah berprofesi sebagai tentara, yang dominan dalam mengajarkan disiplin dan sopan santun pada anak (Serad, 2012). Orang tua mengharapkan anak mereka untuk mematuhi aturan yang telah ditetapkan di rumah serta patuh dan hormat pada orang tua. Anak perlu meminta ijin dan restu pada orang tua apabila mereka hendak melakukan dan memutuskan sesuatu, serta perlu untuk mendengarkan nasihat dari orang tua (Geertz, 1992). Secara bersamaan, orang tua tetap mengharapkan anaknya dapat menampilkan diri yang terbaik dan berani berpendapat dalam masyarakat untuk membuat orang tua mereka bangga sebagai anak tentara.
Masyarakat Magelang, yang merupakan bagian dari subkultur Mancanegari, memang umumnya cenderung lebih berterus terang dan terbuka dalam mengekspresikan pendapatnya (Sartini, 2009; Sutarto, 2004).

Masyarakat Minangkabau juga cenderung bersikap otoriter (conformity) dalam hal pendidikan anaknya. Hal ini serupa dengan fenomena tiger mom yang saat ini banyak terlihat di masyarakat Asia timur, di mana orang tua menetapkan target pencapaian dan disiplin yang tinggi kepada anak-anaknya agar dapat berprestasi dalam bidang akademis (Xie \& Li, 2019). Masyarakat Minangkabau juga menekankan pentingnya rasa saling menghargai dan sopan santun kepada orang yang lebih tua (Amir, 2011; RöttgerRössler dkk., 2013; Diradjo, 2015). Meskipun terbuka kesempatan untuk mengekspresikan pendapat dan berdiskusi, anak tetap perlu mempertimbangkan pendapat dari pihak ketiga yang dituakan dalam mengambil keputusan (Nashori dkk., 2020).

Ketika dilakukan kontrol terhadap variabel covariates diperoleh hasil yang menarik yaitu keempat dimensi, termasuk dimensi nilai budaya individualisme ( $p=0,002)$, menjadi berbeda secara signifikan di wilayah Jabodetabek, Magelang dan Bukittinggi. Ini mendukung hasil dari uji hipotesis bahwa memang terdapat perbedaan antara nilai budaya dan pola pengasuhan di wilayah urban dan rural Indonesia.

\section{Kesimpulan}

Pola pengasuhan yang diterapkan orang tua pada anak besar dampaknya pada berbagai aspek perkembangan anak, terutama kognitif, emosi, dan sosial. Penghayatan nilai budaya menjadi faktor yang berpengaruh secara luas, kompleks dan timbal balik terhadap pengasuhan yang diterapkan orang tua. Indonesia dengan 1.340 suku bangsa tentunya memiliki nilai-nilai budaya yang sangat kaya dan beragam yang dapat memengaruhi praktek pengasuhan yang ditunjukkan orang tua, baik di daerah urban maupun rural. Dalam penelitian terhadap masyarakat urban (Jabodetabek) dan rural (Jawa Magelang dan Minangkabau Bukittinggi) kali ini diperoleh sejumlah temuan penting. Hasil penelitian menunjukkan bahwa ada perbedaan nilai budaya dan pola asuh pada kelompok rural dan urban.

Ketika dilakukan perbandingan antar wilayah, tiga dimensi yaitu: nilai budaya kolektivisme (PAI 1) serta sikap pengasuhan conformity dan autonomy (PAI 2) secara signifikan berbeda di masing-masing wilayah. Kelompok Jabodetabek lebih menonjol dalam nilai budaya kolektivisme dibandingkan dua kelompok lain. Partisi- 
pan Magelang menunjukkan sikap pengasuhan conformity yang paling menonjol, dan cukup berimbang dengan pengasuhan autonomy. Dimensi autonomy sendiri didominasi oleh kelompok Jabodetabek. Setelah kontrol variabel covariates dilakukan, barulah dimensi nilai budaya individualisme menunjukkan perbedaan signifikan antar wilayah. Hasil ini dapat menjadi dasar untuk pengembangan penelitian pola pengasuhan asuh urban dan rural di Indonesia selanjutnya.

\section{Keterbatasan dan Saran}

Studi ini dilakukan pada kelompok urban Jabodetabek serta rural Jawa dan Minangkabau, masih sangat terbatas jika dibandingkan suku bangsa di Indonesia yang berjumlah ribuan. Oleh sebab itu, hasil penelitian belum cukup untuk mencerminkan kaitan penghayatan nilai budaya dengan pola pengasuhan di seluruh wilayah Indonesia. Penelitian lanjutan perlu untuk dilakukan, terutama di pulau-pulau luar Jawa, seperti: Kalimantan, Sulawesi, Bali, Papua dan sebagainya. Hal ini karena masing-masing wilayah di Indonesia memiliki keragaman budaya sehingga penerapan pola asuh sehari-hari yang ditunjukkan orang tua pun akan unik dan berbeda. Perlu diperhatikan pula bahwa budaya di Indonesia bisa memiliki subkultur, seperti budaya Jawa dengan subkultur Nagarigung dan Mancanegari yang dapat memiliki penghayatan budaya berbeda satu sama lain.

Karakteristik partisipan dapat diperluas, salah satunya dengan melibatkan lebih banyak ibu bekerja di untuk melihat dinamika penghayatan budaya pada orang tua urban. Lalu perlu diperhatikan pula proporsi jumlah partisipan agar berimbang antar kelompok partisipan. Kuota sampling dapat menjadi salah satu teknik yang digunakan untuk tujuan ini. Studi selanjutnya juga dapat meneliti faktor-faktor lain yang bisa memengaruhi perbedaan sikap pengasuhan orang tua urban dan rural di Indonesia, seperti: faktor psikologis dan faktor sosial-ekonomi.

\section{Daftar Pustaka}

Alegre, A. (2012). The relation between the time mothers and children spent together and the children's traint emotional intelligence. Child \& Youth Care Forum, 41(5), 493-508. https://doi.org/10.1007/s10566-0129180-z

Amir, M. S. (2011). Masyarakat adat Minangkabau. Jakarta: Citra Harta Prima.

Belsky, J. (1984). The determinants of parenting: A process model. Child Development,
55(1),

83-96.

https://doi.org/10.2307/1129836

Bornstein, M. H. (2012). Cultural approaches to parenting. Parenting, 12(2-3), 212-221. https://doi.org/10.1080/15295192.20 12.683359

Bradley, R. H. \& Corwyn, R. F. (2002). Socioeconomic status and child development. Annual Review of Psychology, 53(1), 371-399. https://doi.org/10.1146/annurev.psyc h.53.100901.135233

Brooks, R. (2005). The power of parenting. In S. Goldstein \& R. Brooks (Eds.), Handbook of resilience in children (pp. 297-314). New York, NY: Springer.

Burchinal, M. R., Peisner-Feinberg, E., Pianta, R., \& Howes, C. (2002). Development of academic skills from preschool through second grade: Family and classroom predictors of developmental trajectories. Journal of School Psychology, 40(6), 415-436. https://doi.org/10.1016/s00224405(02)00107-3

Chandra, J. S. (2004). Notions of critical thinking in Javanese, Batak Toba and Minangkabau culture. In B. N. Setiadi, A Supratiknya, W. J., Lonner, \& Y. P. Porrtinga (Eds.), Ongoing themes in psychology and culture. Selected papers from Sixteenth International Congress of the International Association for Crosscultural Psychology. (p. 275-294). Melbourne, FL: International Association for Cross-cultural Psychology. Retrieved from http://www.iaccp.org.

Diradjo, I. D. S. (2015). Tambo Alam Minangkabau. Bukittinggi: Penerbit Kristal Multimedia.

Durgel, E. S., Vijver, F. J. R. \& Yagmurlu, B. (2012). Self-reported maternal expectations and child-rearing practices: Disentangling the associations with ethnicity, immigration, and educational background. International Journal of Behavioral Development, 37(1), 35-42. https://doi.org/ 10.1177/0165025412456145

Dwairy, M., Achoui, M, Abouserie, R., Farah, A., Sakhleh, A. A., Fayad, M., \& Khan, H. K. (2006). Parenting styles in Arab societies: A first cross-regional research study. Journal of Cross-Cultural Psychology, 37(3), $230 \quad$ - 247. https://doi.org/10.1177/00220221062 86922 
Field, A. (2005). Discovering Statistics Using SPSS 2nd Ed. London: SAGE Publication Ltd.

Franke, R. H., Hofstede, G., \& Bond, M. H. (1991). Cultural roots of economic performance: A research note. Strategic Management Journal, 12(1), 165-173. https://doi.org/10.1002/smj.42501209 12

French, D. C., Rianasari, M., Pidada, S., Nelwan, P. \& Buhrmester, D. (2001). Social support of Indonesian and U.S. children and adolescents by family members and friends. Merrill-Palmer Quarterly, 47(3), 377-394. https://doi.org/10.1353/mpq.2001.001 5

Geertz, H. (1992). Keluarga Jawa. Jakarta: Grafiti Pers

Huver, R. M. E., Otten, R., de Vries, H., \& Engels, C. M. E. (2010). Personality and parenting style in parents of adolescents. Journal of Adolescence, 33(3), 395-402. https://doi.org/ 10.1016/j.adolescence.2009.07.012

Keshavarz, S. \& Baharudin, R. (2009). Parenting Style in a Collectivist Culture of Malaysia. European Journal of Social Sciences, 10(1)1, 66-73. Retrieved from http://psasir.upm.edu.my/id/eprint/16 042/

Koentjaraningrat. (1994). Kebudayaan Jawa. Jakarta: PN Balai Pustaka.

Kuntoro, I. A., Peterson, C. C., \& Slaughter, V. (2017). Culture, Parenting, and Children's Theory of Mind Development in Indonesia. Journal of Cross-Cultural Psychology, 48:9, 1389-1409. https://doi.org/10.1177/00220022117 725404.

Kushnick, G. C. (2006). Parent-offspring conflict among the Karo of North Sumatra. Doctoral Dissertation. Seattle, WA: University of Washington. Retrieved from http://search.proquest. com/docview/304967379?accountid=1 4723

Morrison, F. J. (2009). Parenting and academic development. Merrill-Palmer Quarterly, 55, 361-372. Retrieved from https://www.jstor.org/stable/2309626 2 ? seq $=1$

Mulder, N. (1992). Individual and society in Java: A cultural analysis (2nd ed.). Yogyakarta: Gadjah Mada University Press.

Mulder, N. (2000). Inside Southeast Asia: Religion, Everyday Life, Cultural Change. Chiang Mai, Thailand: Silkworm Books.
Na'im, A. \& Syaputra, H. (2010). Kewarganegaraan, Suku Bangsa, Agama dan Bahasa Sehari-hari Penduduk Indonesia: Hasil Sensus Penduduk 2010. Jakarta: Badan Pusat Statistik.

Nashori, H. F., Nurdin, M. H., Herawati, N., Diana, R. R., \& Masturah, A. N. (2020). Keterikatan interpersonal pada beberapa etnis besar di Indonesia. Jurnal Psikologi Sosial, 18(1), 53-63. https://doi.org/10.7454/jps.2020.07

O’Reilly, J. \& Peterson, C. C. (2014). Theory of Mind at Home: Linking Authoritative and Authoritarian Parenting Styles to Children's Social Understanding. Early Child Development and Care, 184(12), 1934-1947.

https://doi.org/10.1080/03004430.20 14.894034.

Prinzie P., Onghena, P., Hellinckx, W., Grietens, H., Ghesquière, P., Colpin, H. (2004). Parent and child personality characteristics as predictors of externalizing problem behaviour in children. European Journal of Personality, 18(2), $73-102$. https://doi.org/ 10.1002/per.501

Rao, N., McHale, J. \& Pearson, E. (2003). Links between socialization goals and childrearing practives in Chinese and Indian mothers. Infant and Child Development, 12(5), 475-492. https://doi.org/ 10.1002/icd.341

Riany, Y.E., Meredith, P. \& Cuskelly, M. (2017). Understanding the Influence of Traditional Cultural Values on Indonesian Parenting. Marriage \& Family Review, 53(3), 207-226. https://doi.org/10.1080/01494929.20 16.1157561.

Röttger-Rössler, B., Scheidecker, G., Jung, S., \& Holodynski, M. (2013). Socializing emotions in childhood: A cross-cultural comparison between the Bara in Madagascar and the Minangkabau in Indonesia. Mind, Culture, and Activity, 20(3), 260-287. https://doi.org/10.1080/10749039.20 13.806551

Rudy, D. \& Grusec, J. E. (2001). Correlates of Authoritarian Parenting in Individulist and Collectivist Cultures and Implicarions for Understanding the Transmission of Values. Journal of CrossCultural Psychology, 32(2), 202-212. Retrieved from: https://journals.sagepub.com/doi/abs/ 10.1177/0022022101032002007 
Sartini, N.W. (2009). Menggali nilai kearifan lokal budaya Jawa lewat ungkapan (bebasan, saloka dan paribasa). Jurnal Ilmiah Bahasa dan Sastra, 5(1), 28-37. Diunduh dari

http://repository.usu.ac.id/bitstream/h andle/123456789/17541/logapr2009-

5\%20(4).pdf;jsessionid=D87B0FFAC61 DF22D35F1DAAA4482E454? sequence= 1

Serad, S. M. (2012) 18+ sepenggal perjalanan [18+ a piece of the journey]. Jakarta, Indonesia: Hastabrata Kencana.

Smokowski, R. P., Bacallao, M. L., Cotter, K. L., \& Evans, C. (2014). The effects of positive and negative parenting practices on adolescent mental health outcomes in a multicultural sample of rural youth. Child Psychiatry and Human Development, 46 (3), 333-345. https://doi.org/10.1007/s10578-0140474-2

Sutarto, A. (2004). Studi pemetaan kebudayaan Jawa Timur (Studi deskriptif pembagian 10 sub kebudayaan Jawa Timur). Laporan penelitian. Jember: Program Studi Antropologi FISIP Universitas Jember.

Triandis, H. C. (1994). Culture and social behavior. New York: McGraw-Hill

Triandis, H., \& Gelfand, M. (1998). Converging measurement of horizontal and vertical individualism and collectivism. Journal of Personality and Social Psychology, $74(1)$, 118-128. https://doi.org/10.1037/00223514.74.1.118

Vafaeenejad, Z., Elyasi, F., Moosazadeh, M., \& Shahhosseini, Z. (2019). Psychological factors contributing to parenting styles: A systematic review. F1000 Research, 7,
906.

https://doi.org/10.12688/f1000resear ch.14978.2

Vinden, P. G. (2001). Parenting Attitudes and Children's Understanding of Mind: A Comparison of Korean American and Anglo-American Families. Cognitive Development, 16(3) 793-809. https://doi.org/10.1016/s08852014(01)00059-4

Weinberg, B.A. (2001). An incentive model of the effect of parental income on children. Journal of Political Economy, 109(2), 266-280. https://doi.org/10.1086/319556

Xie, S. \& Li, H. (2019). 'Tiger Mom, Panda Dad': A Study of Contemporary Chinese Parenting Profiles. Early Child Development and Care, 189(2), 284-300. 10.1080/03004430.2017.1318870

Yamashita, A. (2017). Chapter 6: Jakarta Metropolitan Area. Urban Developmental in Asia and Africa: Geospatial Analysis of Metropolises. Singapura: Springer Nature Singapore Ptc. Ltd.https://doiorg/10.1007/978-981-10-3241-7

Yunus, K. R. M. \& Dahlan, N. A. (2013). Childrearing practices and socio-economic status: Possible implications for children's educational outcome. Social and Behavioral Sciences, 90, 251-259. . https://doi.org/ 10.1016/j.sbspro.2013.07.089

Zevalkink, J., \& Riksen-Walraven, J. M. (2001). Parenting in Indonesia: Inter- and intracultural differences in mothers' interactions with their young children. International Journal of Behavioral Development, 25 (2), 167-175. https://doi.org/10.1080/01650250042 000113 